\title{
A note on verbal agreement in Maung
}

\author{
MARK DONOHUE \\ Department of Linguistics \\ University of Manchester
}

\begin{abstract}
The non-Pama Nyungan languages of the north of Australia are notable for the often elaborate pronominal prefixing that is found on verbs. Most descriptions of this prefixing describe it as following a nominative-accusative pattern, and note that the ordering of the affixes is not fixed: sometimes object precedes subject, sometimes subject precedes object. In this article I demonstrate that the pronominal prefixing found in Maung is a split-ergative system, and that through reference to the alignment categories distinguished by the prefixes we can find a set of principles behind the variation in prefix order, which are modelled in a set of constraints following the principles of Optimality Theory.
\end{abstract}

Maung is a non-Pama-Nyungan language spoken on Goulburn island off the north coast of the Northern Territory in Australia, which displays extensive verbal agreement and a class system, described in Capell and Hinch 1970 (henceforth C\&H). Verbs agree for both subject and object, with tense-suppletive forms that are clearly related to a basic form of the prefix (for example, the present is formed by the addition of $g$ - to the vowel initial prefixes, thus gininga 'He is speaking.', compared with iningan 'He spoke.'). In the class system class I indicates male humans and some other animate (or classificatorily animate) entities, class II is used for human female and other animate entities, class IV for things associated with the earth, class V for trees and parts of trees, and class VI is used for vegetable food and plants. Class III is the plural of classes I and II for humans only; non-human terms in classes I and II do not have a separate plural form. In section 1 of this article I shall exemplify the agreement morphology of Maung, and attempt some morphological analysis of that material beyond that found in $\mathrm{C} \& \mathrm{H}$. Section 2 presents a summary and model of the restrictions on prefix placement, and section 3 examines some of the empirical findings of the morphological reanalysis in the light of recent claims regarding agreement.

\section{MAUNG AGREEMENT PREFIXES}

Maung is a good language with which to begin an investigation into affix-ordering in Australia, since it is, despite its own individual quirks, surprisingly regular in the forms of the affixes and the ability of the prefix clusters to be segmented into separate morphemes for subject and object. In many other Northern Australian languages there is 'contamination' of part of the verb paradigm by other parts (such as in Mangarayi, in which '[s]econd person nonsingular acting on any first person category is equivalent to third person nonsingular subject acting on that first person 
category.' (Merlan 1982: 163), showing contamination of the $2 \mathrm{NS} \rightarrow 1$ combinations from the $3 \mathrm{NS} \rightarrow 1$ part of the paradigm. In Wardaman (Merlan 1994) there is not only contamination from other parts of the same paradigm, but some combinations use irrealis forms of the pronominal prefixes in the realis paradigm, further complicating a description of the system. Such occurrences are not atypical of the northern Australian languages). Maung, on the other hand, appears not to suffer from these sort of complications, having instead a system which is complex, yet without any major traceable irregularities of the sort mentioned above, and without any portmanteau forms that would also obscure an investigation into prefix-ordering.

C\&H state that in the Maung verb '[t]he object prefix precedes the subject prefix.' (1970: 76), and list pronominal forms for subject and object agreement (1970: facing page 68, 76-77), tacitly assuming a nominative-accusative alignment for the prefixes. The pronominal verbal morphology, as presented by $\mathrm{C} \& \mathrm{H}$ for the generic tenses (the most basic forms) is set out in table 1, and does not wholly support C\&H's descriptive statement that allows for a simple division into subject and object sets of prefixes; to avoid prejudicing the outcome I have listed A, S and O (following Dixon 1979; for definitions, see Andrews 1985: 68) in separate columns, awaiting later analysis (there is no split in the intransitive paradigm, as noted by C\&H (1970: 66). The choice to list nonsingular forms before singular ones is purely empirical, and reflects patterns widely attested regarding the relative position on the animacy hierarchy (Silverstein 1976) of these forms.

\begin{tabular}{|c|c|c|c|c|}
\hline & & A & S & $\mathrm{O}$ \\
\hline 1 INCL & & ar- & arg- & arun- \\
\hline 1 EXCL PL & & yar- & yar- & yarun- \\
\hline SG & & $\eta-$ & ya- & yan- \\
\hline $2 \mathrm{PL}$ & & gur- & gur- & gurun- \\
\hline SG & & gu- & an- & gun- \\
\hline PL HUM & CL III & wu- & aw- & awun- \\
\hline 3 (SG) ANIM & CL I & ni- & i- & (j)i- \\
\hline & CL II & ya- & inj- & (j)inj- \\
\hline NONANIM & CL IV & na- & an- & an- / un- \\
\hline & CL V & ya- & ma- & ma- \\
\hline & CL VI & ja- & aw- & aw- \\
\hline
\end{tabular}

TABLE 1. VERBAL PREFIXES IN MAUNG

(the orthography used follows $\mathrm{C} \& \mathrm{H}$, which is roughly according to IPA standards, with $\{\mathrm{j}\}$ representing a palatal glide, $\{\mathrm{dj}\}$ and $\{\mathrm{nj}\}$ representing unit 'palatodental' phonemes, $\{\mathrm{r}\}$ a trill, $\{\mathrm{r}\}$ a retroflex flap and $\{\mathrm{r}\}$ a rhotic continuant, described as being similar to the English sound) 
Various morphophonemic changes found when two prefixes occur together on a transitive verb, and when any prefix interacts with a consonant-initial stem, serve to obscure this rather neat system, but all the changes are transparent, and there are no prefix clusters that can be thought of as being portmanteau forms.

A basic morphophonemic analysis is straightforward in most cases. For the non-third person pronouns $-r$ is used to make a plural form of the corresponding singular pronominal element, thus $g u$ - 2SG.A and $g u-r$-2PL.A. For all the first and second persons, and the class III (third person human plural) prefixes there this a special marker added to the prefix (a prefixal suffix, so to speak) found when the prefix indicates an object (an accusative marker), $-n$ / - un (- $n$ after vowels, un after a consonant, the vowel probably being epenthetic). For the first and second persons the paradigm is thus split between a nominative prefixal form used for the $S$ and A functions, and an accusative form used for $\mathrm{O}$ functions and formed by the addition of the accusative suffix. ${ }^{1}$

With the third person class prefixes the basic paradigm appears to be absolutive-ergative, with suppletive forms for ergative and absolutive functions (generally; the class I ergative prefix is apparently related to the absolutive one). The class III forms (plural animate) act as a bridge between these two systems, the root forms of the prefixes showing an ergative-absolutive split ( $a w$ - for $\mathrm{S}$ and $\mathrm{O}, w u$ - for $\mathrm{A}$ ), but with the absolutive prefixal form additionally taking the accusative suffix - $(u) n$ when used to refer to an object (thus, awun-). A summary of this reanalysis of the Maung pronominal prefixes as a split-ergative system is shown in table 2.

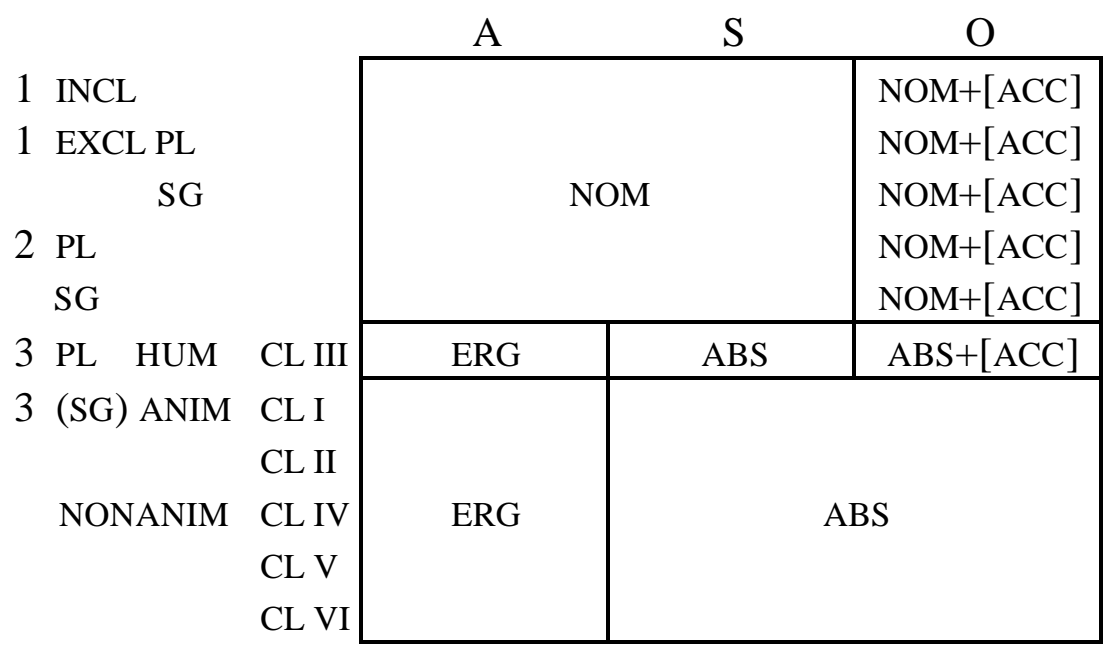

TABLE 2. SPLIT ERGATIVITY AND CATEGORIES IN THE MAUNG VERBAL PREFIXES

1 The second person singular form is more complicated, with what is evidently a suppletive form for the $2 \mathrm{SG}$. $\mathrm{S}$ role; the fact that the 2PL.S form is $g u+r$ - suggests that at an earlier stage the language used $g u$-for $2 \mathrm{SG} . \mathrm{S}$ as well, and that $a n$ is a recent innovation. 
With an intransitive verb, the nominative or absolutive form of the prefix is simply attached to the verb root, with regular morphophonemic changes as required. Examples illustrating some of these points are given in examples (1) - (5) $(\mathrm{C} \& \mathrm{H}, \mathrm{p} 102,40,109,98$ and 115, respectively); a full morphophonemic form has been given in addition to the surface phonological form.

(1) Da gurunman gurunbanawun.

da [gur-un]-ma-n [gur-un]-bana-wu-n

SUBORD [2PL-ACC]-catch-TNS [2PL-ACC]-FUT-hit-TNS ${ }^{2}$

'If we catch you, we shall hit you.'

(2) jejan.

n-i-aja-n

1SG-CL1.ABS-see-TNS

'I see him'

(3) Jandi janilagadjbun?

yandi [ya-n]-ni-lagadjbu-n

who [1SG-ACC]-CL1.ERG-call-TNS

'Who called me?'

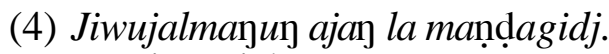

Ji-wu-jalmanu-n ajan la mạ̣dagidj

CL1.ABS-CL3.ERG-seek-TNS CL1.kangaroo andCL1.bush.tail.wallaby

'(They [sandflies, CL3] used to go) seeking kangaroos and bushy tailed wallabies.'

(5) Awuniuy mada andjila mada maragab.

[aw-un]-i-u-n

[CL3.ABS-ACC]-CL1.ERG-give-TNS

'He gave them his only spear.' mada andjila mada m-aragab

CL5.ART CL5.spear CL5.ART CL5-poor/pity

These five examples show the major patterns found, with examples of first or second person (the nominative-accusative categories) acting on each other and on third persons (the ergativeabsolutive category), and of third persons acting on both the first/second person category) and other third persons, including the class III plurals that show mixed ergative-absolutive and accusative behaviour.

2 I shall gloss all the tense/aspect/mood suffixes simply as 'TNS', avoiding a detailed analysis of their semantic components. 


\section{PREFIX ORDERING}

The relative ordering of these prefixes on a transitive verb is more problematic, with no one order prevailing between the two prefixes used (only two prefixes are ever found on a verb, with the recipient of a ditransitive verb being indexed, and the theme not). Examining the ordering of the prefixes just in terms of the categories $\mathrm{A}, \mathrm{S}$ and $\mathrm{O}$, we arrive at the following table showing pronominal prefixes on the verb, arranged according to the person and number of the subject and object (all classes are treated the same way, as third person affixes, as regards ordering on the verb; similarly, all intransitive verbs are treated in the same way, S-V).

$\begin{array}{cccc}\mathrm{A} \backslash \mathrm{O} & 1 & 2 & 3 \\ 1 & - & \mathrm{O}-\mathrm{V} & \mathrm{A}-\mathrm{O}-\mathrm{V} \\ 2 & \mathrm{O}-\mathrm{V} & - & \mathrm{A}-\mathrm{O}-\mathrm{V} \\ 3 & \mathrm{O}-\mathrm{A}-\mathrm{V} & \mathrm{O}-\mathrm{A}-\mathrm{V} & \mathrm{O}-\mathrm{A}-\mathrm{V}\end{array}$

TABLE 3. AGREEMENT ORDERING ON THE TRANSITIVE VERB IN MAUNG: SYNTACTIC ROLES

Extrapolating from table 3, we can see that essentially the pronominal prefix representing the most highly animate argument (in terms of Silverstein's hierarchy) is always placed closest to the verb; in the event of a tie (two third person arguments indexed), the prefix indicating the $\mathrm{A}$ is closer to the verb than the one referring to the O. Furthermore, when both the actants are first or second person (both speech act participants), then only one prefix, that referring to the $\mathrm{O}$, is found on the verb.

Arranging this data in terms of the nominative, accusative, absolutive and ergative categories that the different persons distinguish, we arrive at table 4 , showing the ordering of the different prefixal categories. ${ }^{3}$

\begin{tabular}{ccc|c}
$\mathrm{A} \backslash \mathrm{O}$ & 1 & 2 & 3 \\
1 & - & ACC-V & NOM-ABS-V \\
2 & ACC-V & - & NOM-ABS-V \\
\cline { 2 - 4 } 3 & ACC-ERG-V & ACC-ERG-V & ABS-ERG-V
\end{tabular}

TABLE 4. AGREEMENT ORDERING ON THE TRANSITIVE VERB IN MAUNG: ALIGNMENT

3 In this table the class III prefixes function as an ergative accusative system, giving independent evidence for the base forms of the prefixes determining the alignment, even though there is an overt accusative morpheme on the prefixes that refer to objects 
The synthesis of the material in tables 3 and 4 is given in section 2 , in which the different restrictions on relative affix positioning in Maung are addressed, showing that reference both to the categories distinguished and the grammatical functions represented is necessary. A model of the variation within the framework of Optimality Theory is presented, and section 4 gives a brief discussion of how the results of the reanalysis of the Maung data pose a problem for a recent model of verbal agreement.

\section{FORMALISING THE CONSTRAINTS}

From table 4 we can see that, in addition to the comments made to table 3, the different cases show different restrictions regarding their placement even when referring to the same syntactic role. Essentially, the accusative prefixes must be initial (furthest from the verb root), and the ergative prefixes must be closest to the verb root. Nominative prefixes always precede the absolutive ones, but we cannot directly compare them with accusative prefixes since they never co-occur; this point, the non-occurrence of * NOM-ACC-V or * ACC-NOM-V verb forms, is addressed below. Absolutive prefixes can appear in any position, and appear to be placed according to the constraints on the ordering of the other pronominal prefixes: they fit in wherever the other prefix (nominative or ergative) cannot be placed.

Comparing these constraints with the intransitive verb forms, which only contain one prefix, we note that the constraint against and ergative prefix appearing initially in a prefix cluster are consistent with their non-occurrence in intransitive verb forms: since there is only one position, it is impossible for the Ergative prefix to appear in any position other than initial, and so their use with intransitive verbs is proscribed.

Examining alternations with at least one argument being third person proves itself to be very useful in determining the constraints on the system. For third person $\rightarrow$ third person we find that the constraint against an ergative prefix occurring initially is sufficient to determine the prefixal orderings. When we have first/second person $\rightarrow$ third person, the constraint requiring a nominative prefix to be initial determines the order, and similarly third person $\rightarrow$ first/second person is ordered by reference to the accusative-first constraint. Given this account of most of the system, we are left only with the first/second person $\rightarrow$ first/second person cases, in which only one prefix is found. Given that we already require a constraint positioning the accusative prefixes initially, and that the Nominative prefixes are only found initially, we can account for these first/second person $\rightarrow$ first/second person forms with the simple assumption that the constraints placing these two different prefixes in initial position are not ranked with respect to each other; that is, they are equally prominent constraints, neither of which can be violated. 
Given this, we predict that, when both a nominative prefix and an accusative prefix are required, because of the categories available to the different persons, only one may appear, so as not to force the other into a noninitial position. ${ }^{4}$ Significantly, the prefix referring to the object is always present, and the one referring to the subject is sometimes omitted, showing that the constraint calling for morphological representation of the object on the verb outranks that requiring subject information. ${ }^{5}$ Although the subject prefixes are not present in these two cases, they are present in the other five person/number combinations (see tables 3 or 4), and so we may posit a low-level constraint requiring representation of the subject, though this is lower-ranked than all the other constraints introduced so far.

Formalising these principles within the language of Optimality Theory (OT) (Prince and Smolensky 1993, and others), the following ranked constraints are called for, in the order shown:

Parse (OBJ) » Align (Acc, L), Align (Nom, L) » Noninitial (Erg) » Parse (SUBJ)

Illustrations of the interaction of these constraints to produce the affixal ordering seen in tables 3 and 4 are given below, in each case presenting the example sentence first (with morpheme-bymorpheme and interlinear glosses), the alignment of the two prefixes involved, the table of constraints that serve to define that affixal combination, and the list of non-optimal candidates generated. One example from each of the four distinct 'areas' of alignment-category interactions shown on table 4 is presented, exemplifying each of the four different prefix-ordering combinations. ${ }^{6}$

4 Again a note on the class III prefixes is in order, since again, they function as if they were absolutive prefixes with respect to this ordering, despite displaying an overt accusative morpheme. This points to a recent spread of the accusative morpheme, and suggests that we are witness to an alignment system in which accusative marking is spreading from the first and second persons to all (or at least more) cases, coexisting with a set of conventions to do with prefix ordering that assumes that the class III prefixes are not accusative.

5 This might be taken as evidence for some sort of constituency (i.e., a VP category), but in the absence of further information on this topic, and the free word order found in Maung, I shall simply refer to the separate grammatical functions.

$6 \mathrm{C} \& \mathrm{H}$ do not provide a complete verbal paradigm illustrating all the person-number-class combinations, but do list the forms of the prefixes when they occur in combinations on verb. Because of this, some of the full verbal forms presented below are not attested in $\mathrm{C} \& \mathrm{H}$, but have been constructed based on existing verbal forms, and the lists of prefix combinations given. The important part of the examples, the relative ordering of the prefixes, is attested in $\mathrm{C} \& \mathrm{H}$ and does not represent any conjecture. 
(6) Janejawn

[na-n]-ni-ajaw-n

1SG-ACC-CL1.ERG-See-TNS

'He saw me.'
A: ERG alignment
O: ACC alignment

(7)

\begin{tabular}{|c|c|c|c|c|}
\hline $\begin{array}{l}{\left[{ }^{'} \operatorname{see}(\mathrm{x}, \mathrm{y}) \text { ', }\right.} \\
\text { 3SG }(\mathrm{x}), 1 \mathrm{SG}(\mathrm{y})]\end{array}$ & $\begin{array}{r}\text { Parse } \\
(\mathrm{OBJ}) \\
\end{array}$ & $\begin{array}{c}\begin{array}{c}\text { Align } \\
(\mathrm{ACC}, \mathrm{L})\end{array} \\
(\mathrm{NOM}, \mathrm{L})\end{array}$ & $\begin{array}{c}\text { Noninitial } \\
\text { (ERG) }\end{array}$ & $\begin{array}{l}\text { Parse } \\
(\text { SUBJ })\end{array}$ \\
\hline $1 \mathrm{SG}-3 \mathrm{SG}-\mathrm{V}$ & & & & \\
\hline $3 \mathrm{SG}-1 \mathrm{SG}-\mathrm{V}$ & & $* !$ & * & \\
\hline $1 \mathrm{SG}-\mathrm{V}$ & & & & $* !$ \\
\hline $3 \mathrm{SG}-\mathrm{V}$ & $* !$ & & $*$ & \\
\hline
\end{tabular}

(8) * Ninanajawn

* Janajawn

* Nejawn

In example (6) we can see that the failure to align the accusative first person prefix leftmost in the prefixal cluster is the cause of the A-O-V candidate failing, and both of the forms with only one pronominal affix are ruled out on the grounds that they do not parse all pronominal information all three failed candidates are shown in (8). Since there are no constraints operating against an O-A$\mathrm{V}$ ordering, this is the option that is realised.

(9) ᄁejawn

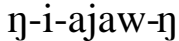

1SG-CL1.ABS-see-TNS

'I saw him.'
A: NOM alignment
O: ABS alignment

\begin{tabular}{|c|c|c|c|c|}
\hline $\begin{array}{l}{\left[{ }^{\prime} \operatorname{see}(\mathrm{x}, \mathrm{y}) ',\right.} \\
1 \mathrm{SG}(\mathrm{x}), 3 \mathrm{SG}(\mathrm{y})]\end{array}$ & $\begin{array}{l}\text { Parse } \\
(\mathrm{OBJ})\end{array}$ & $\begin{array}{c}\text { Align } \\
(\mathrm{ACC}, \mathrm{L})\end{array}, \begin{array}{c}\text { Align } \\
(\mathrm{NOM}, \mathrm{L})\end{array}$ & $\begin{array}{c}\text { Noninitial } \\
\text { (ERG) }\end{array}$ & $\begin{array}{l}\text { Parse } \\
\text { (SUBJ) }\end{array}$ \\
\hline $3 \mathrm{SG}-1 \mathrm{SG}-\mathrm{V}$ & & $* !$ & & \\
\hline 1SG-3SG-V & & & & \\
\hline $3 S G-V$ & & & & $* !$ \\
\hline $1 \mathrm{SG}-\mathrm{V}$ & $* !$ & & & \\
\hline
\end{tabular}




$$
\begin{aligned}
& \text { * Jinajawn } \\
& \text { * Jejawn } \\
& \text { * Jajawn }
\end{aligned}
$$

In (9) we have the same ordering of the pronominal affixes as in (6), despite the reversal of roles; now the constraint calling for nominative prefixes to be leftmost dictates the affix ordering, having ruled out the last two candidates which do not parse all pronominal information.

Jinejawn

ji-ni-ajaw- $\eta$

CL1.ABS-CL1.ERG-See-TNS

'He saw him.'
A: ERG alignment

\begin{tabular}{|c|c|c|c|c|}
\hline $\begin{array}{l}\text { ['see (x,y)', } \\
\text { 3SG (x), 3SG (y)] }\end{array}$ & $\begin{array}{l}\text { Parse } \\
(\mathrm{OBJ}) \\
\end{array}$ & $\begin{array}{cc}\begin{array}{c}\text { Align } \\
(\mathrm{ACC}, \mathrm{L})\end{array} & \begin{array}{c}\text { Align } \\
(\mathrm{NOM}, \mathrm{L})\end{array} \\
\end{array}$ & $\begin{array}{c}\text { Noninitial } \\
\text { (ERG) } \\
\end{array}$ & $\begin{array}{l}\text { Parse } \\
\text { (SUBJ) } \\
\end{array}$ \\
\hline \multicolumn{5}{|l|}{ 3SG.O-3SG.A-V $\quad$ o } \\
\hline 3SG.A-3SG.O-V & & & $* !$ & \\
\hline 3SG.O-V & & & & $* !$ \\
\hline 3SG.A-V & $* !$ & & & \\
\hline
\end{tabular}
O: ABS alignment

(14)

$$
\begin{aligned}
& \text { * Ni(j)ejaw口 } \\
& \text { * Jejawฤ } \\
& \text { * Nejawn }
\end{aligned}
$$

In this third person $\rightarrow$ third person example the constraint against an initial ergative prefix is the determining factor in arriving at the $\mathrm{O}-\mathrm{A}-\mathrm{V}$ order on the verb. Once again, the desire to parse all pronominal information when that does not overtly violate other constraints rules out half the candidates. 
Gunajawn

[gu-n]-ajaw-n

2SG-ACC-see-TNS

'I saw you.'

A: NOM alignment

O: ACC alignment

(16)

\begin{tabular}{|c|c|c|c|c|}
\hline $\begin{array}{l}{\left[{ }^{\prime} \operatorname{see}(\mathrm{x}, \mathrm{y}) \text { ', }\right.} \\
1 \mathrm{SG}(\mathrm{x}), 2 \mathrm{SG}(\mathrm{y})] \\
\end{array}$ & $\begin{array}{r}\text { Parse } \\
(\mathrm{OBJ}) \\
\end{array}$ & 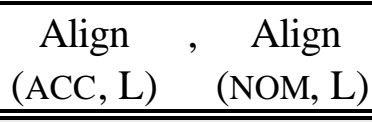 & $\begin{array}{c}\text { Noninitial } \\
\text { (ERG) }\end{array}$ & $\begin{array}{l}\text { Parse } \\
\text { (SUBJ) }\end{array}$ \\
\hline $2 \mathrm{SG}-1 \mathrm{SG}-\mathrm{V}$ & & $* !$ & & \\
\hline $1 \mathrm{SG}-2 \mathrm{SG}-\mathrm{V}$ & & $* !$ & & \\
\hline $2 \mathrm{SG}-\mathrm{V}$ & & & & $*$ \\
\hline $1 \mathrm{SG}-\mathrm{V}$ & $* !$ & & & \\
\hline
\end{tabular}

$$
\begin{aligned}
& * \text { Gunnajawn } \\
& * \text { yagunjawn } \\
& \text { * yajawn }
\end{aligned}
$$

Example (15) is the most interesting one in terms of the operation of constraints and the final outcome. It involves both a nominative-alignment subject and an accusative-alignment object prefix, and shows the need to produce verb forms with a single pronominal prefix, despite this failing to parse all available pronominal information. The reason for this failure to parse the subject is that the orders with two prefixes necessarily fail to align one or the other of the pronominal affixes to the leftmost position, which is called for by the ordering constraints - since Align (ACC, L) and Align (NOM, L) are equally ranked, they are effectively inviolable. This leaves only the highly-ranked constraint against not parsing the object to determine the final successful candidate. Note that, even though the final verb form contains no prefix with pronominal information about the subject, this information is nonetheless functionally transparent, since only a first person subject could be acting on a second person object without a verbal prefix, and the overt accusative morpheme unambiguously marks the second person as object, rather than (necessarily intransitive) subject.

Intransitive verbs, with only one prefix for the subject, are accommodated in the system without problems. Since they do not subcategorise for an object, the constraint Parse(OBJ) does not apply to them, or applies spuriously. The sole pronominal prefix will necessarily be leftmost in the prefix cluster, and not ergative, so again is unproblematic. The only constraint that applies to differentiate forms is Parse(SUBJ), which ensures that there is a pronominal representation of the subject on the verb. 
The tables given in (7), (10), (13) and (16) above show that the system of constraints not only accounts for the relative positioning of two prefixes when (as in most cases) both arguments of a transitive verb are indexed on the verb, but also, with no additional stipulations, correctly models the appearance of only one pronominal prefix when both subject and object are first or second person. This account is possible only if we refer not just to the grammatical functions or syntactic roles that are represented by the prefixes, but also to the alignment category of the prefixing paradigm for that particular point on the animacy hierarchy, since the both $\mathrm{O}-\mathrm{A}-\mathrm{V}$ and $\mathrm{A}-\mathrm{O}-\mathrm{V}$ orderings of the two prefixes are found elsewhere in the same paradigm.

\section{BITTNER AND HALE'S MODEL OF AGREEMENT ORDERING}

An interesting fact that the Maung data forces us to confront is the relative ordering of the ergative and accusative affixes. Bittner and Hale have recently made the strong claim that 'accusative object agreement will be closer to the verb, whereas subject agreement will be more peripheral' (1996: 54). They give the following hierarchy of affixal positions with respect to the verb (the second NOM agreement $(\mathrm{C})$ is the absolutive category ( $\mathrm{S}$ and $\mathrm{O}$ ), whereas the first one (at $\mathrm{I}$ ) is the $\mathrm{S}+\mathrm{A}$ category):

\section{Canonical Agreement Hierarchy (Bittner and Hale 1996: 43) \\ V-D (ACC agreement) < I (ERG or NOM subject agreement) < C (NOM agreement)}

The claim is clearly that accusative agreement is found closer to the verb stem than other pronominal agreement, and yet the prefixing system of Maung both requires the accusative prefix to be leftmost in a cluster and so furthest from the verb stem, but also requires the ergative prefix to be placed closer to the verb stem than any other affixes, including accusative. The relative ordering of pronominal prefixes in Maung is shown in (99) (inverted to be more readily comparable with Bittner and Hale, though the reader should note that Maung pronominal agreement is prefixal, not suffixal).

\section{Maung Agreement Hierarchy V-(ERG agreement $)<($ ABS subject agreement $)<($ ACC or NOM subject agreement $)$}

Not only is the ergative agreement position inside the accusative one, rather than outside it, but additionally the $(\mathrm{S}+\mathrm{A})$ nominative and ergative agreement positions are in demonstrably separate positions, and the nominative subject agreement position is outside the absolutive (= Bittner and Hale's C NOM) agreement position. Languages such as Maung show that the tendencies described 
by Bittner and Hale are only that, and are a long way from representing universal constraints on language. As a result, they are beyond the purvey of Universal grammar, and affix-ordering can be accounted for with language-specific parameters, such as the relatively-ranked set of constraints that I have described above with respect to Maung. Since these are language-specific, it is to be expected that other languages will use them with a different ranking, or utilise different constraints entirely.

\section{References}

Andrews, Avery D. 1985. The major functions of the noun phrase. In Timothy Shopen, ed, Language Typology and syntactic description: Volume I, clause structure, 62-154. Cambridge University Press.

Bittner, Maria and Ken Hale. 1996. The structural determination of Case and Agreement. Linguistic Inquiry 27 (1): 1-68.

Capell, A. and H. E. Hinch. 1970. Maung grammar, texts and vocabulary. The Hague: Mouton.

Dixon, R.M.W. 1979. Ergativity. In Language 55 (1): 59-138.

1980. The languages of Australia. Cambridge: Cambridge University Press.

Merlan, Francesca. 1982. Mangarayi. Lingua descriptive series, vol 4. Amsterdam: North Holland publishing company.

1994. A grammar of Wardaman, a language of the Northern Territory of Australia. Berlin: Mouton de Gruyter.

Prince, Alan, and Paul Smolensky. 1993. Optimality theory: constraint interaction in generative grammar. MS, Rutgers University and University of Colorado.

Silverstein, M. 1976. Hierarchy of features and Ergativity. In R.M.W. Dixon, ed., Grammatical categories in Australian languages: 112-171. Canberra: AIAS. 